\title{
A Wideband Low-Pass Filter for Differential Mode Distortion
}

\author{
M. Brejcha
}

\begin{abstract}
This paper deals with the solution for a wideband low-pass filter that can be used for filtering the input currents of switching converters, which are distorted by the switching frequency of PWM. Initially, the filter was proposed for the special type of AC converter, which is described in the paper. However, these solutions can also be used in the inputs of active PFC converters and in the outputs of PWM converters, where there are similar problems with switching frequency.

The frequency band of the filter is given by the switching frequency of the filtered device and by the demands of EMC standards. This makes the filter able to work in the frequency band from $10 \mathrm{kHz}$ to $30 \mathrm{MHz}$. To ensure such a frequency band, the filter should be proposed with two sections, each for a specific part of the band.
\end{abstract}

Keywords: filter, filtering, low-pass, wideband, EMC, differential mode.

\section{Introduction}

Each realization of a passive filter is affected by the frequency dependence of the circuit component. The value of the main parameter of a component depends on other parasitic properties. When considering a coil, the main parameter is the inductance, and the parasitic parameters are the resistivity of the wires and the capacity among the turns. The resistivity affects the quality factor of the coil, and the capacity defines its serial resonant frequency. Further we will deal with the common circuit parts in passive filters, which are the coils and the capacitors. The equivalent circuits of both circuit parts are depicted in Figure 1. The use of coils and capacitors is limited by the resonant frequency, because when they achieve this frequency their reactance changes sign. The values of the parasitic parameters are associated with the size and construction of the circuit part. It can be said that the size of capacitors and coils are related to the value of the main parameter and the required reactive power. In case of inductors, if inductance value was increased at the same reactive power, then the size of the coil would have to be bigger. As stated above, the value of the parasitic parameters (resistance and capacitance) would be increased.

Ordinary filters are usually proposed for filtering the distortion from $150 \mathrm{kHz}$ to $30 \mathrm{MHz}$. This frequency band is defined in the EMC standards. These filters are not difficult to design, because the frequency boundaries are relatively close. The circuit parts are relatively small, and their parasitic properties do not affect the frequency response so much.

A problem arises when we try to reduce the cutoff frequency of the filter, because we have to increase the inductance and capacitance values. A filter with a relatively low cut-off frequency had to be used for the special AC converter shown in Figure 2.
This four-quadrant converter is based on the topology of a buck-converter, which is widely used in DC circuits. The amplitude of the output fundamental harmonic voltage is proportional to the duty-cycle of the switching. To obtain the fundamental harmonic function, the output filter has to be able to filter the switching frequency (about $20 \mathrm{kHz}$ ). In this case we should design the filter as two or more parts, each for a specific frequency band.

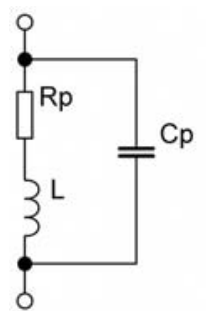

a)

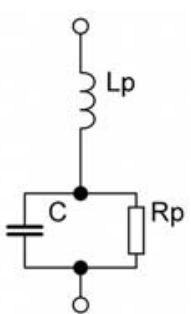

b)
Fig. 1: Equivalent circuits for a) inductors and b) capacitors

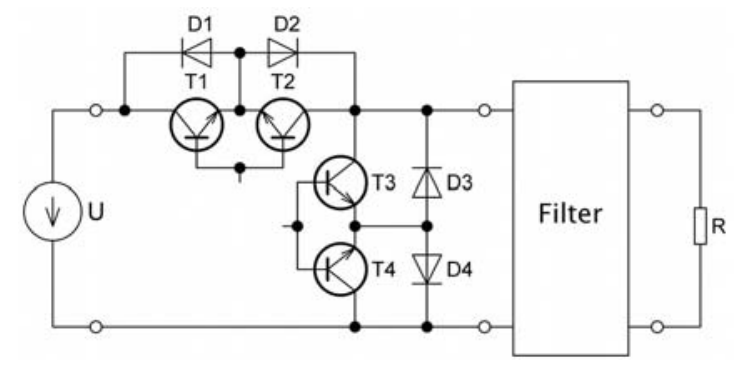

Fig. 2: An AC converter based on a buck-converter

\section{Dependency of the parameters on frequency}

All circuits parts used in the proposed filter were measured to obtain the dependency of the main parameter on frequency. We used $10 \mathrm{nF}$ and $680 \mathrm{nF}$ foil 
capacitors and two handmade $56 \mu \mathrm{H}$ and $3.18 \mathrm{mH}$ inductors in the filter. We plotted the absolute impedance characteristic and the phase angle characteristic in all cases to make it easier to compare the plots with each other.

\subsection{Capacitors}

The characteristic impedance decreases with frequency in both cases of capacitors until the resonant frequency is reached. This corresponds with the equation:

$$
Z \approx X_{C}=\frac{1}{2 \pi \cdot f \cdot C}(\Omega ; \mathrm{Hz} ; \mathrm{F})
$$

In equation $1, f$ is frequency and $C$ is capacity. After reaching the resonant frequency the impedance begins to rise, because the capacitor starts to behave as an inductor. Note that the resonant frequency of the $10 \mathrm{nF}$ capacitor (Figure 3) is higher than the resonant frequency of the $680 \mathrm{nF}$ capacitor (Figure 4). This is because of the size of the parts. The $680 \mathrm{nF}$ has to have larger electrodes to obtain higher capacity. The parasitic inductance increases, because the electrodes also behave as wires.

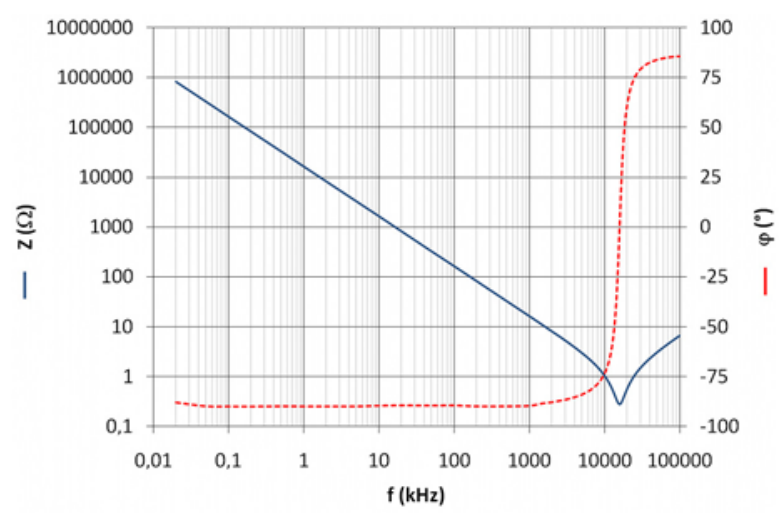

Fig. 3: The impedance of capacitor $10 \mathrm{nF}$

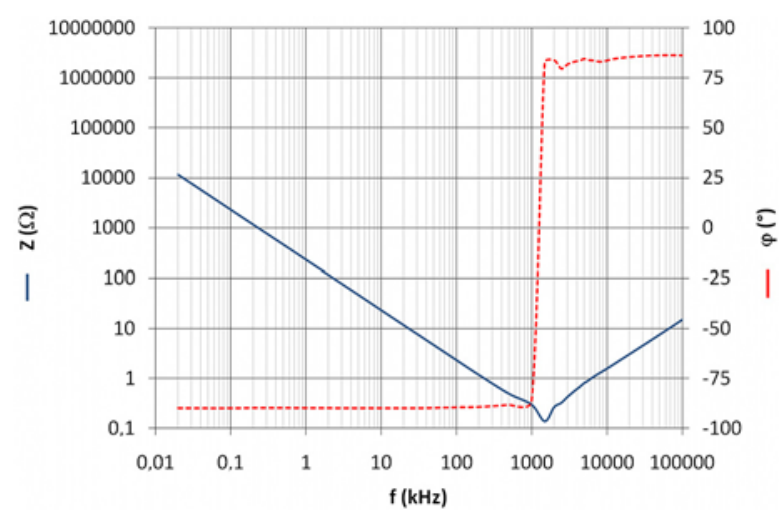

Fig. 4: The impedance of capacitor $680 \mathrm{nF}$

The resonant frequency of a $680 \mathrm{nF}$ capacitor is close to $1 \mathrm{MHz}$. If this capacitor was used in a filter, an unwanted shape of the frequency response would appear above this frequency. $10 \mathrm{nF}$ capacitors have lower parasitic inductance, and they can be used up to $10 \mathrm{MHz}$.

\subsection{Inductors}

There is a similar situation in the case of inductors. At the beginning, the trace of the impedance increases in both types of inductors. This corresponds to the equation:

$$
Z \approx X_{L}=2 \pi \cdot f \cdot L(\Omega ; \mathrm{Hz} ; \mathrm{H})
$$

In equation (2), $f$ is the frequency and $L$ is the inductance in the. As in the previous case, after reaching the resonant frequency the parasitic parameters become dominant and the inductor behaves like a capacitor. An inductor with a higher inductance value has a lower resonant frequency. This is easy to understand, when we realize that the smaller inductor has only 10 turns on a ferrite core and the bigger inductor has 110 turns on an iron powder core.

You may observe that some breaks occur in the trace behind the resonant frequency in Figure 6. This is because the length of the coiled wires exceeded the $1 / 4$ of the wave length of the signal. This is another parasitic phenomenon that affects the resulting frequency response of the filter. The inductor in Fiure 6 certainly should not be used for frequencies higher than $500 \mathrm{kHz}$.

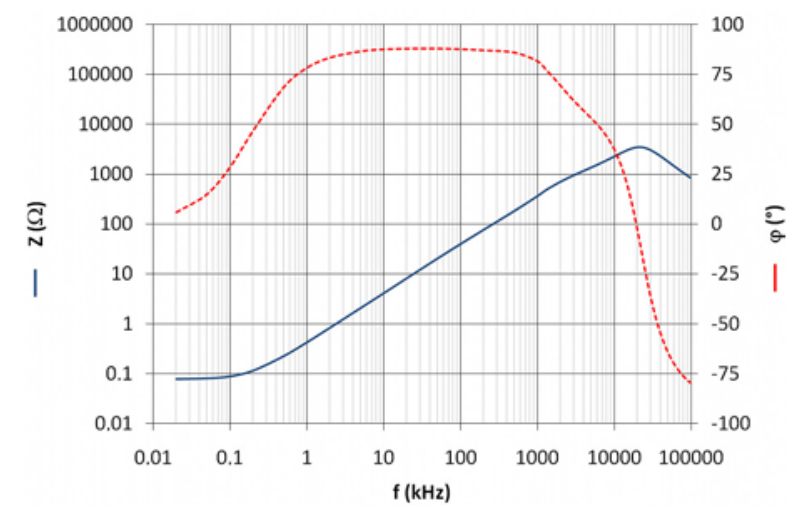

Fig. 5: The impedance of inductor $56 \mu \mathrm{H}$

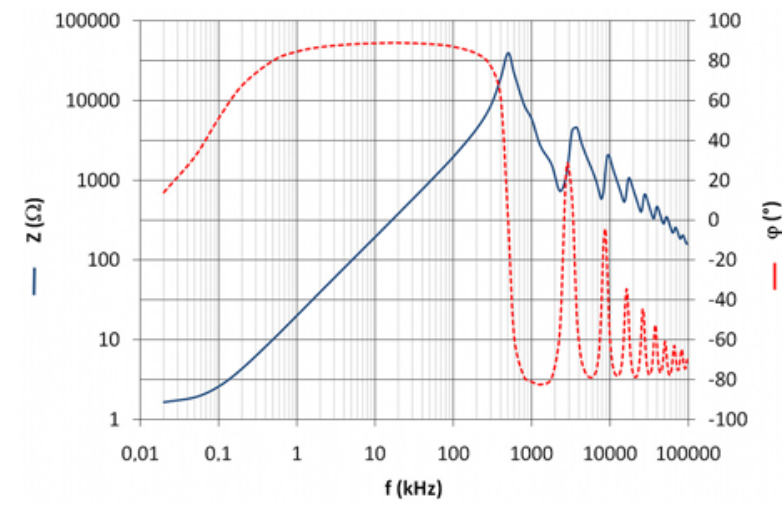

Fig. 6: The impedance of inductor $3.18 \mathrm{mH}$ 


\section{Realization of the filter}

We will further consider the realization of the filter, for which the tolerance scheme is shown in Figure 7. Our goal is to propose a filter with high attenuation between $20 \mathrm{kHz}$ and $30 \mathrm{MHz}$. The terminal resistors will be considered to be $50 \Omega$. If we use the Butterworth approximation for the coefficients of the filter, we obtain the values of the circuit parts for the $\pi$ section shown in Table 1 . These are the same values of the inductors and capacitors as were measured in section 2. Their frequency characteristics are shown in Figure 4 and Figure 6.

Table 1: Filter realization by Butterworth Approximation

\begin{tabular}{|c|c|c|c|c|}
\hline$R 1(\Omega)$ & $C 1(\mathrm{nF})$ & $L 1(\mathrm{mH})$ & $C 2(\mathrm{nF})$ & $R 2(\Omega)$ \\
\hline 50 & 680 & 3.18 & 680 & 50 \\
\hline
\end{tabular}

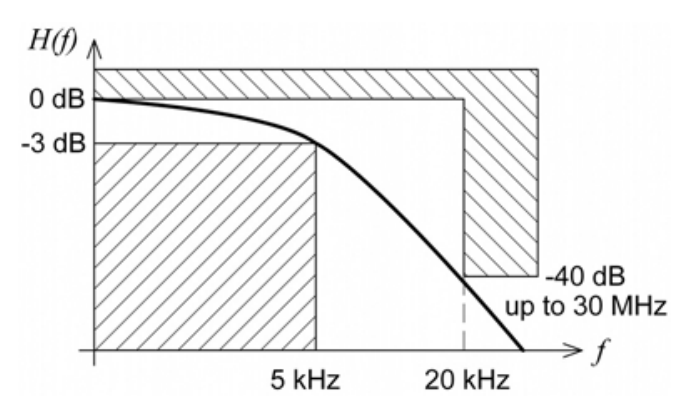

Fig. 7: Prescribed tolerance scheme for the filter

The reader will have noticed that this realization of the filter can be used only up to approximately $1 \mathrm{MHz}$. Above this frequency, the attenuation of the filter will begin to decrease. To solve this problem we should add another section of the filter, which will work well between $1 \mathrm{MHz}$ and $30 \mathrm{MHz}$ and does not affect the previous section of the filter.

\subsection{The corrective section of the filter}

The corrective section of the filter can be just of the $2^{\text {nd }}$ order, because it needs to hold only high attenuation at high frequency. The high level of attenuation should be reached by the previous low-frequency section.

The first task is to ensure that the corrective section of the filter does not affect the previous section. This can be achieved by a progressive sequence of the sections. If the cut-off frequency of the corrective section is much higher than the cut-off frequency of the filter, then it does not affect the passband. The influence of the corrective section is then negligible, and the filter behaves as if it were terminated by $R 1$ and $R 2$. This is because the values of inductors and capacitors in the corrective section are then much lower than in the filter. Lower values of the main parameters also mean lower values of the parasitic parameters of the circuit parts. We propose a cut-off frequency at $100 \mathrm{kHz}$ for this design of a corrective section.

The next task is to reflect the impedance of the filter section in solution of the corrective section. We cannot count with the terminal resistor $R 1$ anymore, because the impedance of the filter section is not negligible. However the resulting output impedance of the filter is very low at high frequency, because of the large value of capacitor $C 2$. We can therefore consider the input impedance of the corrective section to be zero. We therefore design the section with terminal resistors 0 and $R 2$. The proposed values of the circuit parts, using the Butterworth approximation for both sections, are shown in Table 2 .

Table 2: Filter design with corrective section

\begin{tabular}{|c|c|c|c|c|c|c|}
\hline $\begin{array}{c}R 1 \\
(\Omega)\end{array}$ & $\begin{array}{c}C 1 \\
(\mathrm{nF})\end{array}$ & $\begin{array}{c}L 1 \\
(\mathrm{mH})\end{array}$ & $\begin{array}{c}C 2 \\
(\mathrm{nF})\end{array}$ & $\begin{array}{c}L 2 \\
(\mu \mathrm{H})\end{array}$ & $\begin{array}{c}C 3 \\
(\mathrm{nF})\end{array}$ & $\begin{array}{c}R 2 \\
(\Omega)\end{array}$ \\
\hline 50 & 680 & 3.18 & 680 & 56 & 10 & 50 \\
\hline
\end{tabular}

Fig. 8: Filter topology

\subsection{Prototype of the filter}

Using the method described above, we made a prototype of the filter, which is shown in Figure 9. The filter was made to attenuate the differential mode of distortion. The circuit parts were soldered on the top layer of the PCB. The bottom layer was grounded to the shielding. To attenuate possible interference among the circuit parts, the inductor $L 1(3.18 \mathrm{mH})$ was enclosed in its own shielding. The input and the output of the filter were realized by BNC connectors.

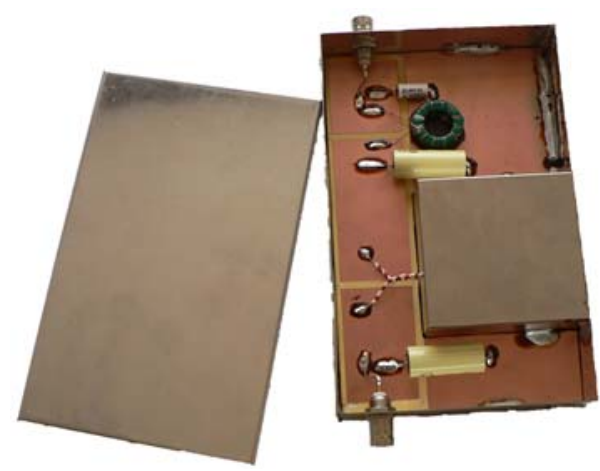

Fig. 9: The prototype of the filter 
The frequency response of the filter prototype was measured, and the result is shown in Figure 10. There is only low attenuation in the passband up to $5 \mathrm{kHz}$. This corresponds to the demands for the design. After crossing the cut-off frequency, the trace begins to decrease. The maximum of attenuation is close to $100 \mathrm{~dB}$ at approximately $200 \mathrm{kHz}$. The corrective section should also function at this frequency. Attenuation higher than $85 \mathrm{~dB}$ is then held up to $30 \mathrm{MHz}$.

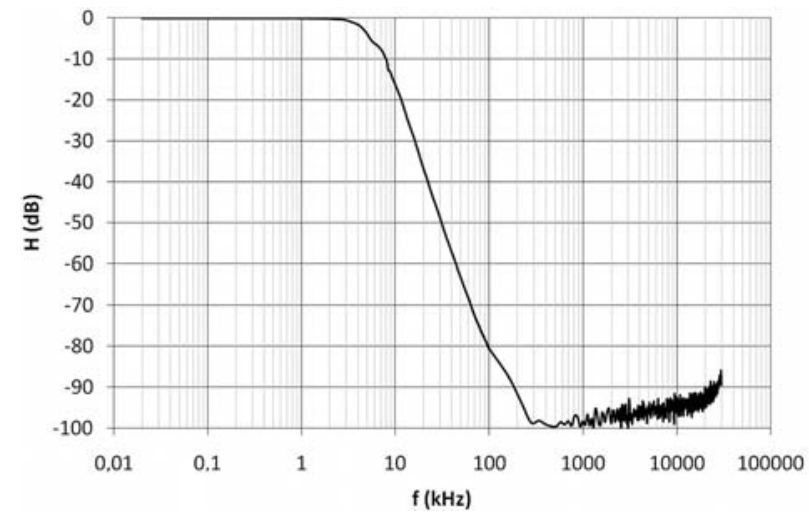

Fig. 10: Frequency response of the filter prototype

\section{Conclusion}

We have described a method for designing a wide band low-pass filter by adding the corrective section to the filter. The resulting frequency response of the filter meets the requirements, and high attenuation has been retained up to $30 \mathrm{MHz}$. However, the other circuit parts make the filter more expensive and increase its size. The larger dimension of the filter can lead to other problems with parasitic effects.

\section{Acknowledgement}

The research presented in this paper was supported by the Czech Ministry of Education under grant No. MSM6840770017 — Rozvoj, spolehlivost a bezpečnost elektroenergetických systémů.

\section{References}

[1] Cetl, T., Papež, V.: Konstrukce a realizace elektronických obvodů. Praha: Vydavatelství ČVUT, 2002. 263 s. ISBN 80-01-02463-6.

[2] Bičák, J., Laipert, M., Vlček, M.: Lineární obvody a systémy. Praha : Česká technika — nakladatelství ČVUT, 2007. 204 s.

ISBN 978-80-01-03649-5.

[3] Davídek, V., Laiperet, M., Vlček, M.: Analogové a číslicové filtry. Praha: Nakladatelství ČVUT, 2006. 345 s. ISBN 80-01-03026-1.

[4] Chen, W.-K., et al.: Passive, Active and Digital Filters. $3^{\text {rd }}$ ed. Chicago, U.S.A. : CRC Press, 2009. ISBN 978-1-4200-5885-1.

[5] Faktor, Z.: Transformátory a cívky. dotisk 1. vyd. Praha : Ben, 2002. 400 s. ISBN 80-86056-49-X.

\begin{abstract}
About the author
Michal BREJCHA was born 26 March 1983 in Prague. He attended SPŠE Františka Křižíka secondary school between 1999 and 2003, where he studied the electrotechnic section. He then started to study electric power engineering at CTU in Prague. There he was awarded his bachelor degree and his master degree in Electrotechnology in 2006. He is now studying as a $\mathrm{PhD}$ student in the same department of the Faculty of Electrical Engineering.
\end{abstract}

\section{Michal Brejcha}

E-mail: brejcmic@fel.cvut.cz

Dept. of Electrotechnology

Czech Technical University

Technická 2, 16627 Praha, Czech Republic 